Article

\title{
Interference Competition for Mutualism between Ant Species Mediates Ant-Mealybug Associations
}

\author{
Yongheng Liu, Chong $\mathrm{Xu}$, Qiuling Li and Aiming Zhou * \\ Hubei Insect Resources Utilization and Sustainable Pest Management Key Laboratory, College of Plant Science \\ and Technology, Huazhong Agricultural University, Wuhan 430070, China; \\ yonghengliu@webmail.hzau.edu.cn (Y.L.); hzauxuchong@163.com (C.X.); 17537161706@163.com (Q.L.) \\ * Correspondence: zhouam@mail.hzau.edu.cn
}

Received: 14 November 2019; Accepted: 23 January 2020; Published: 1 February 2020

\begin{abstract}
Ant-hemipteran mutualism has been well documented, and many studies have reported the interference competition between ant species for the mutualism. However, little is known on how this interference competition impacts the reciprocally beneficial association. Previous studies demonstrated that the invasive mealybug Phenacoccus solenopsis (Tinsley) has established close mutual relationship with the ghost ant Tapinoma melanocephalum (Fabricius). The sympatric ants, Paratrechina longicornis (Latreille) and Tetramorium bicarinatum (Nylander) were frequently observed to compete for nutrient honeydew produced by P. solenopsis with T. melanocephalum. Herein, we investigated the effects of interference competition between the ant species on the ant-mealybug interactions. Phenacoccus solenopsis benefited from the tending by T. melanocephalum and P. longicornis. Interference competition between T. melanocephalum and P. longicornis interrupted the mutualism, suppressed the trailing activity of both species, but negligibly influenced the parasitism of Aenasius bambawalei Hayat, a solitary endoparasitoid of $P$. solenopsis. Harmonia axyridis, a predator of $P$. solenopsis, showed a significant avoidance when encountering with T. melanocephalum or P. longicornis, but not T. bicarinatum. Ant workers showed higher aggressiveness and lower exploratory activity when T. melanocephalum encountered P. longicornis. However, competition between T. melanocephalum and T. bicarinatum seldom influenced the trailing and exploratory activity of T. melanocephalum. It is concluded that interference competition for mutualism between ant species can mediate ant-mealybug associations and the fitness of mealybug colony. Our results also demonstrate that the effects of interference competition between ant species on ant-mealybug mutualism are varied among ant species.
\end{abstract}

Keywords: ant-mealybug mutualism; ant interference competition; Phenacoccus solenopsis; natural enemies

\section{Introduction}

Mutualism, which is defined as the reciprocally beneficial interaction between two species, is an important ecological interaction [1,2]. Mutualism between ants and hemipterans is common in natural environment and plays key roles in ecological processes [2-4]. Ants tend and protect honeydew-producing hemipterans from predators and parasitoids in a wide range of ecosystems [5]. In return, hemipterans provide ants with honeydew as a crucial food source [6,7]. Currently, the broad ecological effects of ant-hemipteran interactions have been increasingly recognized and documented [7-11]. The mutual relationship would be stable when the trade-off between the cost and benefit is in balance [12]. However, this mutual relationship can be strongly influenced by the local biotic neighborhoods in which it occurs [13]. The beneficial effects of mutualist species on each other can vary along with the changes in biotic factors, such as the density of associated species, seasonality, 
spatial distribution, identity of species involved and quality of host plants [13-18]. The outcome of the interactions can vary from mutualistic to commensalistic or even antagonistic, depending on the ecological context and the interacting species [19].

Although many studies have elucidated the ant-hemipteran interactions and their ecological outcomes, relatively few studies have explored the various outcomes resulting from the competitive mutualism among the interactional species. It is accepted that competition is an important force in natural communities [20,21]. Previous studies have reported the competition among hemipterans to exploit the same resources for the mutualistic services of ants [22,23]. Protection efficiency of Lasius niger (Linnaeus) differs among aphid species [24]. Ants usually preferentially tend the aphid species that produce more honeydew or excrete ant-preferred sugars [21,25]. Subsequent studies have revealed that the recruitment response of ants is directly influenced by the quality and quantity of honeydew [26-28]. These results suggest that the effect of the competition may depend on the relative attractiveness of aphids to ant species involved in the mutual interactions.

In comparison with the competition for ant tending among different hemipterans, the interference competition between ant species for mutualist-provided resources has been less studied. Such competition is particularly acute between invasive and native ant species. Intense interspecific competition between Solenopsis invicta Buren and native ants for carbohydrate sources from honeydew-producing hemipterans widely exists in both its native and invasion regions [4]. Solenopsis invicta suppresses native ants by monopolization and competition for mutualism with honeydew-producing hemipterans [29-31]. Besides, interspecific competition from ecologically dominant native ants can affect the invasion success of invasive species [4]. Due to its advantages in competition for space and food exploitation, native ant Tapinoma nigerrimum (Nylander) notably reduces the likelihood of incipient colony establishment and survival of Argentine ant Linepithema humile Mayr [32]. Honeydew-producing citrus mealybug, Pseudococcus citriculus Green, can associate with various mutualistic ant species, including Lasius niger and Pristomyrmex pungens Mayr. The territories of these two ant species are completely separated, and there are occasional territory takeovers of one ant species by the other. Lasius niger is considered as a more effective mutualistic partner than $P$. pungens because of its higher aggressiveness [33]. These results suggest that interference competition between ant species may be an important index to evaluate the intensity of ant-hemipteran association. Previous studies have described the interference competition between ant species for mutualist-provided carbohydrates [7,29,34]. However, it remains unclear how the interference competition affects involved ant communities, including foraging activity and aggression. More importantly, the direct effects of the interference competition on outcome of the mutual association are largely unknown.

The mealybug Phenacoccus solenopsis Tinsley (Hemiptera: Pseudococcidae) is a polyphagous invasive species in China. It has established widely mutualistic relationships with a wide range of ant species, including S. invicta, T. melanocephalum, P. longicornis, T. bicarinatum and Pristomyrmex pungens in ecosystems [35-38]. The ghost ant T. melanocephalum is one of the most dominant native ant species in the areas invaded by S. invicta [39]. Tapinoma melanocephalum also competes for honeydew produced by mealybugs with other native ant species [31]. Currently, few studies have reported the effects of the interference competition between the native ant species, including T. melanocephalum, P. longicornis and T. bicarinatum, on ant-mealybug interactions. Understanding the response of each partner in the beneficial associations to ant competition is critical to clarifying how resource competition between ant species regulates the ecological interactions. Herein, we conducted a series of laboratory experiments to test the effect of ant interference competition on the colony growth of $P$. solenopsis and the performance of natural enemies of mealybugs. We also evaluated how interference competition mediates the trailing activity, aggressiveness index and exploratory behavior of these three ant species. We hypothesize that T. melanocephalum competes with P. longicornis and T. bicarinatum for mutualist that provides carbohydrate resources. The interference competition between ant species would affect the outcome of ant-mealybug mutualism. Our results may provide more accurate information for 
better understanding the mechanism by which interspecific competition among ant species mediates ant-hemipteran mutualism.

\section{Materials and Methods}

\subsection{Plants and Insects}

Cotton plants (Jimian 11, non-transgenic, Academy of Agriculture and Forestry Sciences, Hebei, China) were grown in soil media (organic matter $\geq 20 \%$; Jiangsu Peilei Technology Development CO., LTD) within plastic flowerpots. Each plant used in the experiment was approximately $30-40 \mathrm{~cm}$ in height with 15-20 true leaves. Phenacoccus solenopsis colonies were collected from a cotton field in Huazhong Agricultural University and transferred to cotton plants in flowerpots. Sixty 1st instar mealybug nymphs were placed on cotton plants and raised for several generations in the laboratory at the temperature of $26 \pm 2{ }^{\circ} \mathrm{C}$ and relative humidity of $60-70 \%$. The parasitoid Aenasius bambawalei and predator Harmonia axyridis were also collected from cotton field. Both parasitoid and predator colonies were fed mealybug nymphs in the laboratory at $26 \pm 2{ }^{\circ} \mathrm{C}$ and under an LD 16:8 h photoperiod.

Sympatric ant colonies of Tapinoma melanocephalum, Paratrechina longicornis and Tetramorium bicarinatum were collected from the suburb of Wuhan. Ant colonies were separated from the soil by dripping water into the plastic boxes until the colonies floated [40]. Ants were then removed and reared in plastic boxes with tubes filled with distilled water. The colonies were subsequently divided into several small colony fragments by weight using a microbalance (Sartorius BSA 224S, Elk Grove, IL, USA). Ant colony fragment of each species consisted of 1 queen and approximately 2500 workers. Each ant colony fragment was placed in a $9-\mathrm{cm}$ plastic Petri dish and then introduced into a plastic container $(22 \times 15 \times 7 \mathrm{~cm})$ as an artificial nest [17]. Each ant colony fragment was only used once in all experiments. Ant colonies were supplied weekly with live mealworm larvae (Tenebrio molitor L.; Coleoptera: Tenebrionidae) and $50 \mathrm{~mL} \mathrm{10 \%} \mathrm{honey} \mathrm{water} \mathrm{solution.} \mathrm{All} \mathrm{ant} \mathrm{colonies} \mathrm{were} \mathrm{reared} \mathrm{in} \mathrm{the}$ laboratory at $26 \pm 2{ }^{\circ} \mathrm{C}$ and relative humidity of $60-70 \%$.

\subsection{Effects of Ant Competition on Mealybug Colony Growth under Predation}

Each potted cotton plant was held in a plastic tray $(42 \times 26 \times 18 \mathrm{~cm})$ and covered with nylon netting surrounded by a wooden cage $(90 \times 90 \times 100 \mathrm{~cm})$. The potted plants were randomly arranged. Thirty 2 nd instar mealybugs were transferred to each caged plant. The ant colony fragment was placed into a small plastic container $(22 \times 15 \times 7 \mathrm{~cm})$, and connected with the plant tray by a silicone tube $(0.8 \mathrm{~cm}$ in diameter and $10 \mathrm{~cm}$ in length) (Figure S1). To prevent the ants from escape, Teflon (Sigma Aldrich, Shanghai, China) was applied halfway up the inner surface of each ant colony container and plant tray. This treatment design allowed ant workers to approach the mealybug colonies directly through the plant trunk. After $24 \mathrm{~h}$, two lady beetle larvae were introduced on the plants as predators. The ant colony was provided with $50 \mathrm{~mL}$ of water every 2 days. A completely randomized design was conducted for this experiment, including T. melanocephalum, P. longicornis, T. bicarinatum, a combination of T. melanocephalum and P. longicornis colonies, and a combination of T. melanocephalum and T. bicarinatum colonies. No ant tending was used as a control. Each treatment was replicated 12 times, and the number of live mealybugs per plant was recorded after six weeks. The colony growth rate of mealybugs was defined as the final population density divided by the initial population density.

\subsection{Effects of Ant Competition on Parasitism of Mealybugs by A. bambawalei}

The effects of ant competition on the parasitism of $A$. bambawalei were also evaluated by the caged bioassay described above. We transferred the 3rd instar mealybugs to caged plants (60 individuals per plant). The ant colony fragment was then connected with the plant tray. The ants were given two mealworms and $50 \mathrm{~mL}$ water every two days. Two fertilized female parasitoids were released on each plant after $24 \mathrm{~h}$. Five treatments of ant-tending and a control were implemented as described in 2.2. Each treatment was replicated 12 times. All surviving mealybugs and mummified mealybugs on 
each plant were collected and counted after two weeks. The parasitism percentage was defined as the number of mummified mealybugs divided by the total number of mealybugs on each plant.

\subsection{Effects of Interference Competition on Ant Trailing Activity}

The trailing activity of each ant species was determined in laboratory assay. One cotton plant was placed in the plastic tray. The 3rd instar mealybugs were introduced to the cotton plants (60 individuals per plant) and allowed to acclimate and feed for $24 \mathrm{~h}$. The ant colony fragment was deprived of any carbohydrate source for $12 \mathrm{~h}$ and then connected with the plant tray. Workers could enter into the plant tray and move toward the plant through the outside of the pot. Ant tending treatments were conducted as follows: T. melanocephalum; P. longicornis; and a combination colony of T. melanocephalum and P. longicornis. The similar experiments were repeated with T. melanocephalum; T. bicarinatum; and a combination colony of T. melanocephalum and T. bicarinatum. Each treatment was replicated 15 times. The trailing activity of ants was evaluated on the plants by counting the number of trailing ants moving up and down the plant trunk for 5 min after $24 \mathrm{~h}$.

\subsection{Effects of Interference Competition on Predator Performance}

The effects of ant competition on the performance of lady beetles were tested by using a behavior observation apparatus described previously [38,41]. Lady beetle females were provided choices to forage and lay eggs in two arenas, in one of two jointed plastic boxes $(40 \times 25 \times 30 \mathrm{~cm})$. One arena was occupied by ants, and ants were excluded from the other arena. Each box has an open window in the upper half of the jointed wall. Teflon was applied halfway up the inside of each box below the window to prevent ants from crossing from one area into the other. Lady beetle adults could still have access to both arenas by climbing or flying across the open window (Figure S2). A 14-cm Petri dish coated with Teflon was placed in the center of each box, and a cotton leaf with 60 3rd instar mealybugs was placed in the dish. The petiole of a cotton leaf was wrapped with moist cotton to maintain turgor. At the beginning of the experiment, 100 ant workers were placed into each box together with 10 lady beetle adults. Teflon was used to prevent mealybugs from escaping and ants from invading. Five treatments were implemented to determine the effects interference competition on predator performance: T. melanocephalum/no ants; P. longicornis/no ants; T. bicarinatum/no ants; T. melanocephalum-P. longicornis/no ants; and T. melanocephalum-T. bicarinatum/no ants. Each comparison was replicated 12 times. The number of ladybeetles in each arena and the number of eggs laid in the Petri dishes were counted at after $48 \mathrm{~h}$.

\subsection{Aggressiveness Evaluation between the Ant Species at Individual Level}

The aggressiveness between different ant species at individual level was quantified with the protocol described by Errard and Hefetz [42] and Tsutsui et al. [43]. One ant worker was randomly selected from the three ant species. Two individual workers were paired together in a Petri dish (diameter $=3.5 \mathrm{~cm}$ ). To prevent the ants from climbing out, the Petri dish was coated with Teflon. All tested individuals were derived from different colonies. The assigned ant workers were allowed to acclimate for one minute in the Petri dish before the test. The behavioral interactions between the workers were scored in 5 min: 1: avoidance (keep away from each other); 2 : brief touch ( $\leq 1 \mathrm{~s}$ ); 3 : long touch (>1 s); and 4: attack postures (bite). Aggressiveness was determined in both T. melanocephalum-P. longicornis interaction and T. melanocephalum-T. bicarinatum interaction. Fifty trials were implemented for each treatment. The aggressiveness index was calculated by the following formula as previously described by Errard and Hefetz [42] (1). The percentage of aggressiveness level was calculated and analyzed by Formula (2):

$$
\begin{gathered}
\frac{\sum_{i=1}^{n} \delta_{i} t_{i}}{T} \\
\frac{\delta_{i} t_{i}}{\sum_{i=1}^{n} \delta_{i} t_{i}}
\end{gathered}
$$


where $\delta_{i}$ represents the score we evaluated in the attack interaction, $t_{i}$ means the duration of each behavioral interaction, $n$ means the number of replications in each treatment and $T$ is the total time for each trial.

\subsection{Effects of Interference Competition on the Exploratory Activity of Ants}

The exploratory activity of ant species was assessed using a modified apparatus originally described by Grangier and Lester [44]. Three cotton plants were placed in a plastic tray $(75 \times 44 \times 12$ $\mathrm{cm}$ ) and each plant was $20 \mathrm{~cm}$ apart. Each plant was considered as a different foraging arena for ant colonies: original arena, medium arena and extended arena (Figure S3). Each cotton plant was infected with 60 3rd instar mealybugs before the test. The mealybugs were allowed to acclimate for $24 \mathrm{~h}$ on the plants. The ant colony fragment was then connected with the plant tray. To prevent ant escape, the inside of the tray was treated by Teflon. The outside of the pot located in medium arena and extended arena was also treated by Teflon respectively to discourage foraging path of ant to the plants. This treatment makes the plant located in original arena become the only access for workers to foraging. Each two contiguous plants were connected by a wooden bridge (25 cm length). The exploratory activity of ants on plant in different foraging arenas was scored: 1: original arena; 2 : medium arena; 3: extended arena. Exploratory activity of ants in the original arena was defined as the number of workers moving up and down the plant trunk in $5 \mathrm{~min}$. The exploratory activity of the ants in medium arena and extended arena was defined as the number of workers moving toward and away from the plant on bridge 1 and bridge 2, respectively, in 5 min (Figure S3). The exploratory activity was calculated by using the modified formula proposed by Errard and Hefetz [42] (3). The percentage of exploratory level of each ant species was calculated by using formula (4). The treatments were the same as those for trailing activity test described previously in experiment 2.4. Each treatment was repeated by 10 trials.

$\delta_{i}$ represents the score evaluated in the exploratory behavior; $n_{i}$ means the number of workers in each foraging arena; $T$ is the total time for each trial; and $\mathrm{m}$ means the number of replications for each treatment.

$$
\begin{gathered}
\frac{\sum_{\mathrm{i}=1}^{m} \delta_{i} n_{i}}{T} \\
\frac{\delta_{i} n_{i}}{\sum_{\mathrm{i}=1}^{m} \delta_{i} n_{i}}
\end{gathered}
$$

\subsection{Statistical Analysis}

For experiment 2.2 and 2.3, to satisfy the precondition of variance analysis, colony growth rate of mealybug was treated by $\log 10$-transformation. Parasitism by A. bambawalei was treated by the arcsine square root-transformation. One-way ANOVA was used to compare the variance in means of mealybug colony growth rate and parasitism among different ant tending treatments. An LSD-test was performed for multiple comparisons of mealybug colony growth rate and parasitism between the ant treatments. For experiment 2.4, an Independent sample $t$-test was used to analyze the difference in ant trailing activity between single colony and combined colony. For experiment 2.5, a Paired sample t-test was performed to analyze the difference in number of lady beetle adults and eggs between ant included arena and ant excluded arena. For experiment 2.6, an Independent sample $t$-test was used to determine ant aggressiveness index and aggressiveness level between T. melanocephalum-P. longicornis competition and T. melanocephalum-T. bicarinatum competition. For experiment 2.7, an Independent sample t-test was used to analyze the difference in ant exploratory activity and exploratory level between single colony treatment and combined colony treatment. All statistical analyses were conducted with SPSS, version 19.0 (SPSS Inc., Chicago, IL, USA). 


\section{Results}

\subsection{Mealybug Colony Growth under Predation}

The results showed that the growth of mealybug colony was significantly different under the tending by different ant species in the presence of predation $\left(\mathrm{F}_{5,66}=9.603, \mathrm{P}<0.001\right)$. Compared with no ant tending, mealybug colony growth was significantly improved by tending of T. melanocephalum, P. longicornis and a combination of T. melanocephalum-T. bicarinatum (Figure 1A, TM: P $<0.001$; PL: $P=$ 0.001; TM-TB: $\mathrm{P}<0.001$; LSD-test). No positive effects on mealybug colony growth were observed for tending by combination of T. melanocephalum-P. longicornis or T. bicarinatum alone (Figure 1A; TM-PL, $\mathrm{P}=0.566 ; \mathrm{TB}, \mathrm{P}=0.680 ;$ LSD-test).

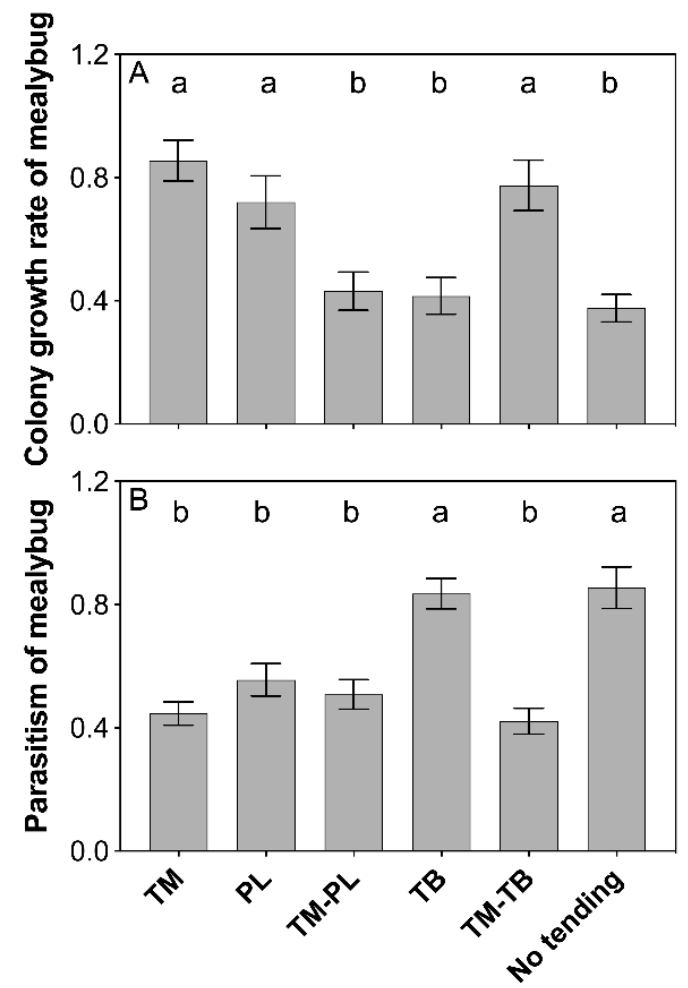

Figure 1. Effects of interference competition on mealybug populations. (A) colony growth rate of mealybug; (B) parasitism of mealybug. The data are presented as the mean $\pm \mathrm{SE}$. Bars sharing the same letters indicate no significant differences among the treatments $(P>0.05)$. Colony growth rate was treated by log10-transformation, and the percent of parasitism on the mealybugs was treated by the arcsine square root-transformation. Tapinoma melanocephalum, Paratrechina longicornis, Tetramorium bicarinatum, Tapinoma melanocephalum-Paratrechina longicornis confrontation and Tapinoma melanocephalum- Tetramorium bicarinatum confrontation were abbreviated into TM, PL, TB, TM-PL and TM-TB, respectively.

\subsection{Parasitism by the Parasitoids}

Percentage of parasitism varied among ant tending treatments (Figure $1 \mathrm{~B} ; \mathrm{F}_{5,66}=14.635, \mathrm{P}<0.001$ ). Compared with no ant tending, parasitism was largely reduced when mealybugs were tended by $T$. melanocephalum, P. longicornis and a combination of T. melanocephalum-P. longicornis, and a combination of T. melanocephalum-T. bicarinatum ( $P<0.001$, respectively; LSD-test), while tending by T. bicarinatum, had no significant effect on parasitism $(P=0.784 ; L S D$-test $)$. 


\subsection{Ant Trailing Activity}

Both T. melanocephalum and P. longicornis exhibited higher trailing activities under single colony treatment than under combined colony treatment (Figure 2A; TM: $t=2.900, d f=28, P=0.007$; PL: $t=$ $2.298, d f=28, P=0.029$; independent sample $t$-test). Furthermore, the trailing activity of T. melanocephalum was almost not influenced by interference competition with T. bicarinatum (Figure 2B; TM: $t=-1.319, d f$ $=28, P=0.198$; independent sample $t$-test); however, that of $T$. bicarinatum rapidly decreased when they encountered T. melanocephalum colony (Figure 2B; TB: $t=4.507, d f=28, P<0.001$; independent sample $t$-test).
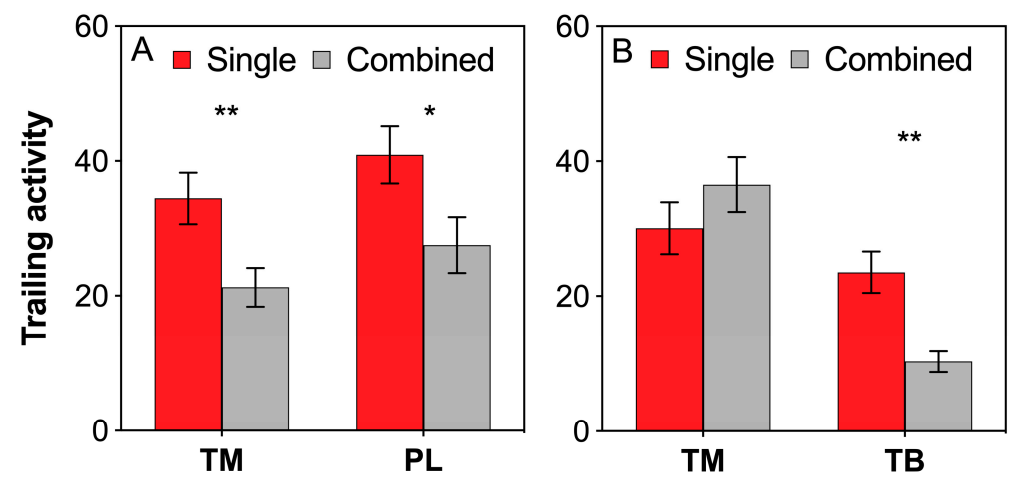

Figure 2. Effects of interference competition on ant trailing activity. (A) T. melanocephalum-P. longicornis interaction; (B) T. melanocephalum-T. bicarinatum interaction. The data are presented as the mean $\pm \mathrm{SE}$. Asterisk $\left({ }^{*}\right.$ or $\left.{ }^{* *}\right)$ on bars indicates significant differences between the treatments $(P<0.05$ or $P<0.01)$. Tapinoma melanocephalum, Paratrechina longicornis and Tetramorium bicarinatum were abbreviated into TM, PL and TB, respectively.

\subsection{Predator Performance}

Lady beetle adults apparently avoided the foraging arena occupied by workers of T. melanocephalum, P. longicornis, T. melanocephalum-P. longicornis, and T. melanocephalum-T. bicarinatum combined colonies (Figure 3A; TM: $t=-3.153, d f=11, P=0.009$; PL: $t=-2.401, d f=11, P=0.035$; TM-PL: $t=-2.493, d f=$ $11, P=0.030$; TM-TB: $t=-2.597, d f=11, P=0.025$; paired sample $t$-test). Tending by T. bicarinatum had little effect on the predation of lady beetles (Figure 3A; TB: $t=0.813, d f=11, P=0.433$; paired sample $t$-test). Lady beetles produced fewer eggs in the arenas with workers of T. melanocephalum, P. longicornis and a combination of T. melanocephalum-T. bicarinatum (Figure 3B; TM: $t=-3.806, d f=11, P=0.003$; PL: $t=-2.332, d f=11, P=0.040$; TM-TB: $t=-2.858, d f=11, P=0.016$; paired sample $t$-test). Oviposition of lady beetles was not significantly influenced by T. bicarinatum or combination of T. melanocephalumP. longicornis (Figure 3B; TB: $t=-0.879, d f=11, P=0.398$; TM-PL: $t=-0.617, d f=11, P=0.550$; paired sample t-test).

\subsection{Ant Aggressiveness}

The aggressiveness index between T. melanocephalum and P. longicornis was definitely higher than that between T. melanocephalum and T. bicarinatum (Figure 4A, $t=5.147, d f=28, \mathrm{P}<0.001$; independent sample $t$-test). Aggressive acts in avoidance occurred more frequently in T. melanocephalum-T. bicarinatum interaction, while brief touch occurred more frequently in T. melanocephalum-P. longicornis interaction (Figure 4B; $t=-4.796, d f=28, \mathrm{P}<0.001 ; t=2.772, d f=28, \mathrm{P}=0.01$, respectively; independent sample t-test).

\subsection{Ant Exploratory Activity}

Both T. melanocephalum and P. longicornis workers showed much higher exploratory activities in single colony than in combined colony treatment (Figure 5A; TM: $t=3.153, d f=18, \mathrm{P}=0.006$; PL: $t=$ 
2.756, $d f=18, \mathrm{P}=0.013$, respectively; independent sample $t$-test). Interference competition between $T$. melanocephalum and T. bicarinatum significantly reduced the exploratory activity of T. bicarinatum but not T. melanocephalum (Figure 5B; TB: $t=4.067, d f=18, \mathrm{P}=0.001$; TM: $t=-0.431, d f=18, \mathrm{P}=0.672$, respectively; independent sample t-test).
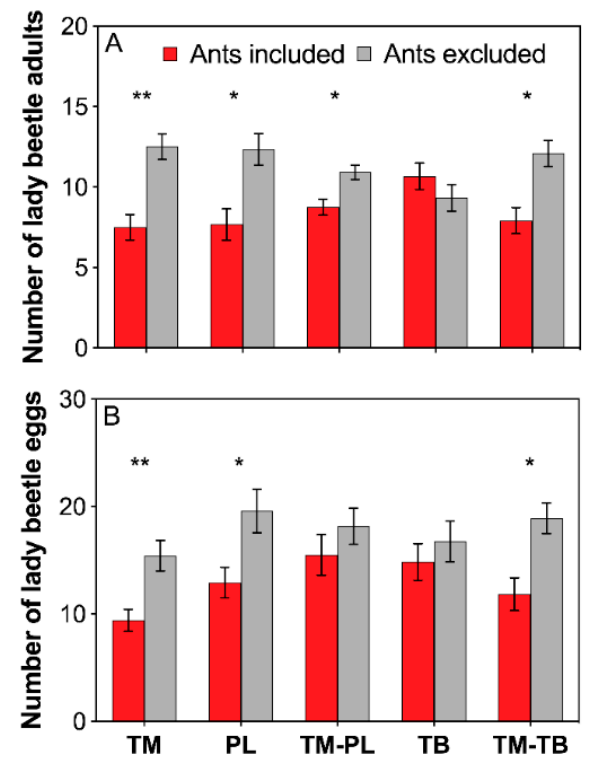

Figure 3. Effects of interference competition on predator performance. (A) number of lady beetle adults; (B) number of lady beetle eggs. The data are presented as the mean \pm SE. Asterisk $\left(^{*}\right.$ or **) on bars indicates significant differences between ant treatments $(P<0.05$ or $P<0.01)$. Tapinoma melanocephalum, Paratrechina longicornis, Tetramorium bicarinatum, Tapinoma melanocephalum-Paratrechina longicornis confrontation and Tapinoma melanocephalum- Tetramorium bicarinatum confrontation were abbreviated into TM, PL, TB, TM-PL and TM-TB, respectively.
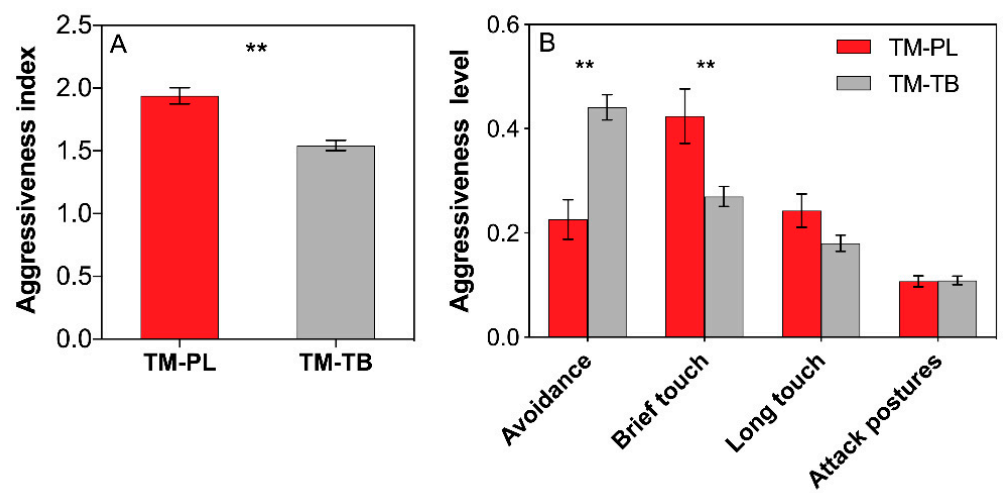

Figure 4. Effects of interference competition on ant aggressiveness. (A) aggressiveness index; (B) percentage aggressiveness level. The data are presented as the mean \pm SE. Asterisk $\left({ }^{* *}\right)$ on bars indicate indicates significant differences between the ant treatments $(P<0.01)$. Tapinoma melanocephalum-Paratrechina longicornis confrontation and Tapinoma melanocephalumTetramorium bicarinatum confrontation were abbreviated into TM-PL and TM-TB, respectively.

T. melanocephalum possessed higher exploratory level in original arena but lower exploratory level in extended arena when treated by combination of T. melanocephalum and P. longicornis (Figure 6A; $t=-3.375, d f=18, \mathrm{P}=0.003 ; t=2.342, d f=18, \mathrm{P}=0.031$, respectively; independent sample $t$-test). The same case of $P$. longicornis was observed when treated by combined colony (Figure $6 \mathrm{~B} ; t=-3.559$, $d f=18, \mathrm{P}=0.002 ; t=2.690, d f=18, \mathrm{P}=0.015$, respectively; independent sample $t$-test). No significant 
difference in exploratory level of T. melanocephalum was found between single and combination of T. melanocephalum- T. bicarinatum in each foraging arena (Figure $6 \mathrm{C} ; t=-1.135, d f=18, \mathrm{P}=0.271$; $t=-0.409, d f=18, \mathrm{P}=0.687 ; t=1.581, d f=18, \mathrm{P}=0.131$, respectively; independent sample $t$-test). T. bicarinatum showed lower exploratory level in extended arena when treated by combination of $T$. melanocephalum and T. bicarinatum (Figure $6 \mathrm{D} ; t=2.536, d f=18, \mathrm{P}=0.021$; independent sample $t$-test).
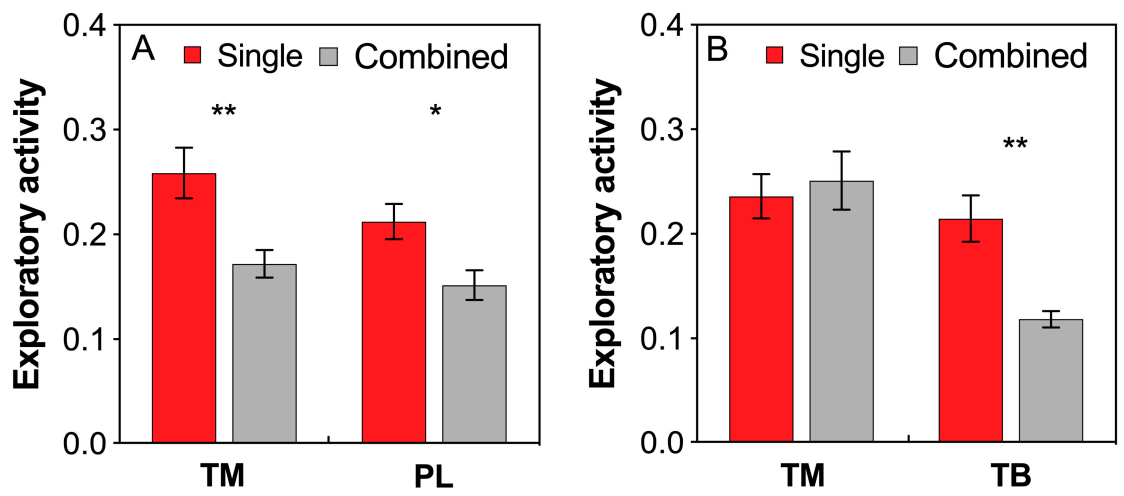

Figure 5. Effects of interference competition on ant exploratory activity. (A) T. melanocephalum- $P$. longicornis interaction; (B) T. melanocephalum-T. bicarinatum interaction. The data are presented as the mean \pm SE. Asterisk $\left({ }^{*}\right.$ or $\left.{ }^{* *}\right)$ on bars indicates significant differences between the treatments $(P<$ 0.05 or $P<0.01$ ). Tapinoma melanocephalum, Paratrechina longicornis and Tetramorium bicarinatum were abbreviated into TM, PL, and TB respectively.
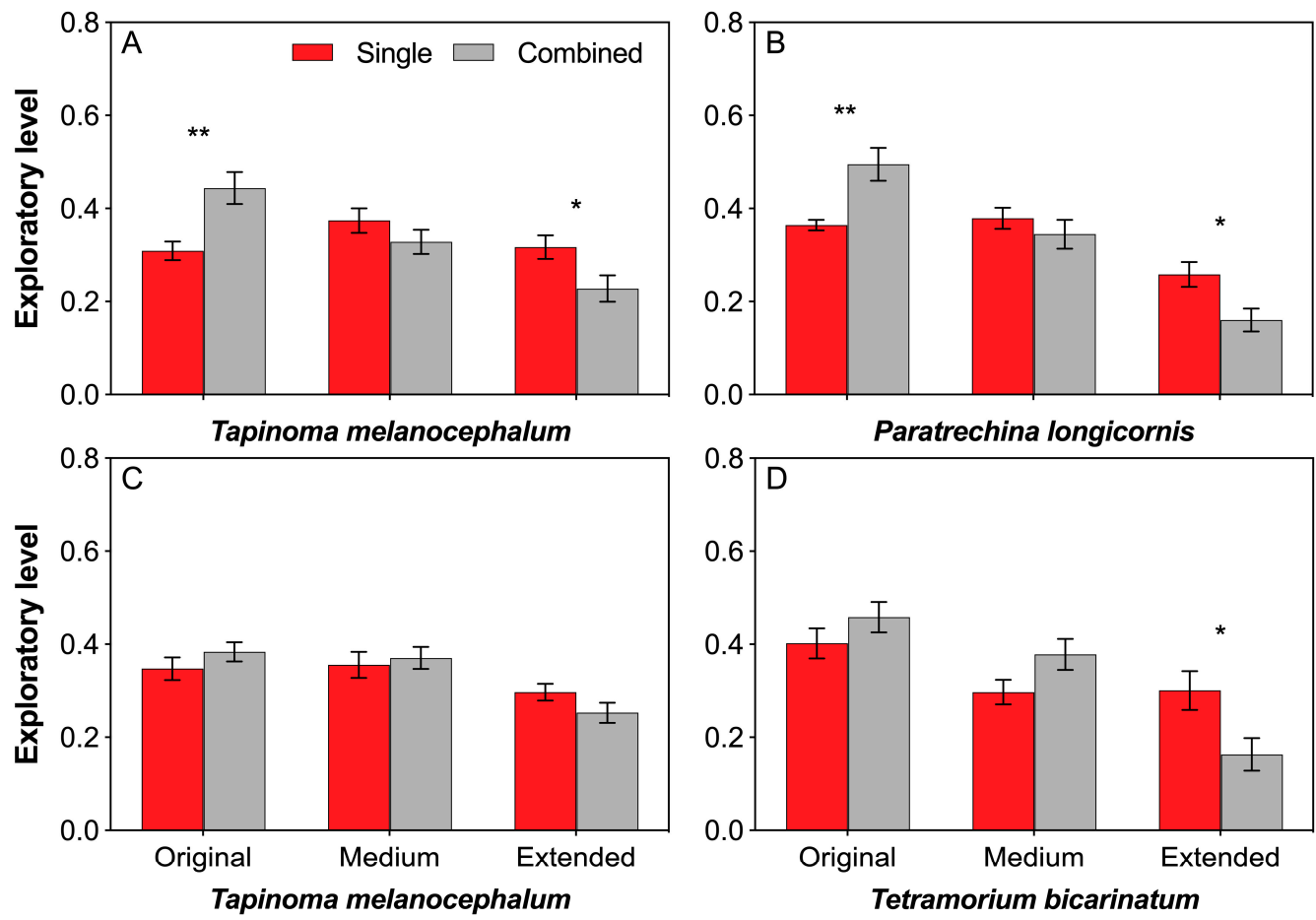

Figure 6. Effects of interference competition on ant exploratory level. (A,B) T. melanocephalum-P. longicornis interaction, (A) exploratory level of T. melanocephalum; (B) exploratory level of P. longicornis. (C,D) T. melanocephalum- T. bicarinatum interaction, (C) exploratory level of T. melanocephalum; (D) exploratory level of T. bicarinatum. The data are presented as the mean \pm SE. Asterisk (* or **) on bars indicates significant differences between the treatments $(P<0.05$ or $P<0.01)$. 


\section{Discussion}

Animals usually experience imbalance of food resources in the ecosystem, which often restricts colony abundance and limit the maximum fitness [45]. Honeydew produced by hemipterans is considered as an important carbohydrate resource for many honeydew collection ants [7]. Due to its sugar and amino acid composition, honeydew is essential for ant colony growth and survival [46,47]. Furthermore, the benefits of mutualist-provided carbohydrates to the successful invasion of ants have been extensively studied $[4,29,48,49]$. Although many studies have illustrated the interference competition between invasive and native ants for the limited carbohydrates produced by hemipterans, few studies have examined the competition between native ant species, and it remains unclear how this interference competition affects the outcome of ant-hemipteran mutualism. This study for the first time provided experimental evidence that the interference competition between native ant species mediates the outcome of beneficial services of ants.

Intensity of ant-hemipteran interactions varies with ant species. When tending the same hemipteran species, different ant species may have different levels of aggressiveness against the enemies of hemipterans and thereby different extents of interference with prey consumption by predators and oviposition by parasitoids [33,50]. Lasius japonicus and P. pungens differ in aggressiveness towards Aphis spiraecola enemies. Compared with L. japonicas, P. pungens shows lower aggressiveness, and thus, has a lower extent of interference with parasitoid oviposition [51]. Our results showed that the colony growth of P. solenopsis was improved by T. melanocephalum and P. longicornis tending. However, the positive effects of ant tending on mealybug colony growth disappeared when two ant species competed for mutualism, suggesting that the interference competition between two native ant species restrains their mutualistic efficiency. In addition, the tending ant species significantly affected the percentage parasitism by parasitoids, with more mealybug mummies in T. bicarinatum tended colonies, which also suggests that $T$. melanocephalum and P. longicornis take more aggressive actions against parasitoids than T. bicarinatum. Unexpectedly, we found that T. melanocephalum-P. longicornis and T. melanocephalum-T. bicarinatum competitions did not influence the parasitism of parasitoids. This result may be attributed to the distinctive approach of T. melanocephalum against parasitoids compared with that of other native ants. Workers of T. melanocephalum could effectively utilize their pygidial gland secretions as an alarm-defense system during aggressive confrontations [52]. A. bambawalei showed strong avoidance to pygidial gland secretions of T. melanocephalum [53]. Therefore, repression of parasitism by $A$. bambawalei was also observed even when there was intense competition between $T$. melanocephalum and P. longicornis because of the presence of T. melanocephalum secretions.

The intensity of interference competition between ant speices can be revealed by the foraging activity of ant workers $[29,54]$. Honeydew exploitation by T. melanocephalum significantly declined when S. invicta was introduced, and the foraging activity of T. melanocephalum increased when fire ants were excluded [31]. Prevalence of dolichoderine ant Dorymyrmex bureni declined in areas invaded by S. invicta due to the competition for mutualist-provided carbohydrates [29]. In our study, interference competition reduced the recruitment of T. melanocephalum, P. longicornis and T. bicarinatum for carbohydrates produced by mealybugs. However, the trailing activity of T. melanocephalum was not influenced by T. melanocephalum and T. bicarinatum interaction, suggesting a stronger antagonism action between T. melanocephalum and P. longicornis than between T. melanocephalum and T. bicarinatum. This result was also confirmed by subsequent aggressiveness test, which revealed a great passivity of the T. bicarinatum workers during confrontation with T. melanocephalum workers. Furthermore, the performance of predators was definitely impeded by T. melanocephalum and P. longicornis, but not by T. bicarinatum. Competition between T. melanocephalum and T. bicarinatum did not obviously affect the negative effects of T. melanocephalum on predators, which also suggests that the competitiveness in T. melanocephalum and T. bicarinatum interaction is relatively low and the protection effect on mealybugs depends on ant species. A similar study reported that due to the more effective patrolling of L. humile than Tapinoma sessile on plant surfaces to protect honeydew-producing hemipterans, Aphis gossypii was less negatively affected by enemies when tended by L. humile [55]. Different ant species may have 
significantly different protection effects on myrmecophilous aphids from natural enemies, which may depend on the potential level of aggressiveness of ants and their foraging strategies when collecting honeydew [56]. Predators produce fewer eggs in arenas occupied by T. melanocephalum or P. longicornis, but no noticeable difference was observed in arenas with T. melanocephalum and P. longicornis interaction, suggesting that the negative effects of T. melanocephalum or P. longicornis on predators were weakened by the interference competition.

Carbohydrates serve as a principal metabolic fuel, and carbohydrate scarcity may hinder the aggressive activity of ants to a greater extent than deficiency of protein or other nutrients essential for their growth. Invasive ants and co-occurring native ants showed significantly different behavior responses under competition for limited food resource [57]. Carbohydrate scarcity limits the aggression and activity of invasive ant Linepithema humile [34]. However, the foraging activity and aggressiveness of the native ant Prolasius advenus were increased under carbohydrate scarcity [44]. Our results revealed a significant difference in aggressiveness index between the two pairs of antagonistic competition. The differences in aggressiveness of ants may impact their competitive ability for food resources. Interference competition reduced the exploratory level of the three ant species, particularly that of $T$. bicarinatum. The number of trailing workers of T. bicarinatum showed a sharp decline in $T$. melanocephalum and T. bicarinatum combined colony compared with a single colony. These results suggest that competition between ant species for honeydew resource produced by hemipterans may inhibit their protection of honeydew producing insects.

\section{Conclusions}

In conclusion, our results showed different efficiencies of two ant interference competition models on the outcome of mutual interactions. The dominant native ant $T$. melanocephalum competes for access to mutualist-provided carbohydrates with P. longicornis and T. bicarinatum and suppresses T. bicarinatum from this critical resource. Additionally, our results provide novel evidence that competition for mutualist-provided carbohydrates between native ant species can enhance the performance of natural enemies, and in turn affecting the outcome of ant-mealybug mutualism, which may impact on the fitness and invasion process of the invasive mealybug. Currently, most conclusions are based on laboratory evidence, more studies conducted in field are needed to confirm this perspective. These findings may promote our understanding of the significance of interference competition in mediating ecological interactions and arthropod community.

Supplementary Materials: The following are available online at http://www.mdpi.com/2075-4450/11/2/91/s1.

Author Contributions: Y.L., C.X. and A.Z. wrote the manuscript; Y.L., C.X., Q.L. and A.Z. analyzed the data and prepared the figures; A.Z. provided conception and design of research. Y.L., C.X., Q.L. and A.Z. performed the experiments; A.Z. edited and reviewed the manuscript. All authors accepted the final version of the manuscript.

Funding: This study was supported and funded by the National Natural Science Foundation of China (Grant no. 31972342, 31401808), the Natural Science Foundation of Hubei, China (Grant no. 2017CFB441) and Fundamental Research Funds for the Central Universities (Grant no. 2662018JC052).

Acknowledgments: We thank Z.X. Liu from the college of Foreign Languages of HZAU for language modification and Pan Li for the figure polish.

Conflicts of Interest: The authors declare no conflict of interest.

Ethical Approval: This article does not contain any studies with human participants or vertebrate performed by any of the authors.

\section{References}

1. Stachowicz, J.J. Mutualism, facilitation, and the structure of ecological communities. BioScience 2001, 51, 235-246. [CrossRef]

2. Styrsky, J.D.; Eubanks, M.D. Ecological consequences of interactions between ants and honeydew-producing insects. Proc. R. Soc. Lond. B Biol. Sci. 2006, 274, 151-164. [CrossRef] [PubMed] 
3. Brightwell, R.J.; Silverman, J. Invasive Argentine ants reduce fitness of red maple via a mutualism with an endemic coccid. Biol. Invasions 2010, 12, 2051-2057. [CrossRef]

4. Wilder, S.M.; Holway, D.A.; Suarez, A.V.; LeBrun, E.G.; Eubanks, M.D. Intercontinental differences in resource use reveal the importance of mutualisms in fire ant invasions. Proc. Natl. Acad. Sci. USA 2011, 108, 20639-20644. [CrossRef]

5. Renault, C.; Buffa, L.; Delfno, M. An aphid-ant interaction: Effects on different trophic levels. Ecol. Res. 2005, 20, 71-74. [CrossRef]

6. Davidson, D.W.; Cook, S.C.; Snelling, R.R. Liquid-feeding performances of ants (Formicidae): Ecological and evolutionary implications. Oecologia 2004, 139, 255-266. [CrossRef]

7. Stadler, B.; Dixon, A.F.G. Ecology and evolution of aphid-ant interactions. Annu. Rev. Ecol. Evol. Syst. 2005, 36, 345-372. [CrossRef]

8. Kaplan, I.; Eubanks, M.D. Disruption of cotton aphid (Homoptera: Aphididae)-natural enemy dynamics by red imported fire ants (Hymenoptera: Formicidae). Environ. Entomol. 2002, 31, 1175-1183. [CrossRef]

9. Wilder, S.M.; Holway, D.A.; Suarez, A.V.; Eubanks, M.D. Macronutrient content of plant-based food affects growth of a carnivorous arthropod. Ecology 2011, 92, 325-332. [CrossRef]

10. Zhang, S.; Zhang, Y.X.; Ma, K.M. The ecological effects of the ant-hemipteran mutualism: A meta-analysis. Basic Appl. Ecol. 2012, 13, 116-124. [CrossRef]

11. Xu, C.; Su, J.; Qu, X.B.; Zhou, A.M. Ant-mealybug mutualism modulates the performance of co-occurring herbivores. Sci. Rep. 2019, 9, 13004. [CrossRef] [PubMed]

12. Bronstein, J.L.; Wilson, W.G.; Morris, W.F. Ecological dynamics of mutualist/antagonist communities. Am. Nat. 2003, 162, S24-S39. [CrossRef] [PubMed]

13. Cushman, J.H.; Whitham, T.G. Conditional mutualism in a membracid-ant association: Temporal, age-specific, and density dependent effects. Ecology 1989, 4, 1040-1047. [CrossRef]

14. Breton, L.M.; Addicott, J.F. Density-dependent mutualism in an aphid-ant interaction. Ecology 1992, 73, 2175-2180. [CrossRef]

15. Moreira, V.S.; Del-Claro, K. The outcomes of an ant-treehopper association on Solanum lycocarpum St. Hill: Increased membracid fecundity and reduced damage by chewing herbivores. Neotrop. Entomol. 2005, 34, 881-887. [CrossRef]

16. Fagundes, R.; Ribeiro, S.P.; Del-Claro, K. Tending-ants increase survivorship and reproductive success of Calloconophora pugionata Drietch (Hemiptera, Membracidae), a trophobiont herbivore of Myrcia obovata O. Berg (Myrtales, Myrtaceae). Sociobiology 2013, 60, 11-19. [CrossRef]

17. Zhou, A.M.; Kuang, B.Q.; Gao, Y.R. Does the host plant affect the benefits from mutualisms? The invasive mealybug and ghost ant association. Ecol. Entomol. 2015, 40, 782-786. [CrossRef]

18. Pepi, A.A.; Broadley, H.J.; Elkinton, J.S. Density-dependent effects of larval dispersal mediated by host plant quality on populations of an invasive insect. Oecologia 2016, 182, 499-509. [CrossRef]

19. Aranda-Rickert, A.; Fracchia, S.; Yela, N.; Marazzi, B. Insights into a novel three-partner interaction between ants, coreids (Hemiptera: Coreidae) and extrafloral nectaries: Implications for the study of protective mutualisms. Arthropod Plant Interact. 2017, 11, 525-536. [CrossRef]

20. Schoener, T.W. Field experiments on interspecific competition. Am. Nat. 1983, 122, 240-285. [CrossRef]

21. Cushman, J.H. Host plant mediation of insect mutualism: Variable outcomes in herbivore-ant interactions. Oikos 1991, 61, 138-144. [CrossRef]

22. Addicott, J.F. Competition for mutualists: Aphids and ants. Can. J. Zool. 1978, 56, 2093-2096. [CrossRef]

23. Tena, A.; Hoddle, C.D.; Hoddle, M.S. Competition between honeydew producers in an ant-hemipteran interaction may enhance biological control of an invasive pest. Bull. Entomol. Res. 2013, 103, 714-723. [CrossRef] [PubMed]

24. Fischer, M.K.; Hoffmann, K.H.; Völkl, W. Competition for mutualists in an ant-homopteran interaction mediated by hierarchies of ant attendance. Oikos 2001, 92, 531-541. [CrossRef]

25. Cushman, J.H.; Addicott, J.F. Conditional Interactions in Ant-Herbivore Mutualisms. Ant-Plant Interactions; Huxley, C.R., Cutler, D.F., Eds.; Oxford University Press: Oxford, UK, 1991; pp. 92-103.

26. Völkl, W.; Woodring, J.; Fischer, M.; Lorenz, M.W.; Hoffmann, K.H. Ant-aphid mutualisms: The impact of honeydew production and honeydew sugar composition on ant preferences. Oecologia 1999, 118, 483-491. [CrossRef] 
27. Blüthgen, N.; Fiedler, K. Preferences for sugars and amino acids and their conditionality in a diverse nectar-feeding ant community. J. Anim. Ecol. 2004, 73, 155-166. [CrossRef]

28. Zhou, A.M.; Kuang, B.Q.; Gao, Y.R.; Liang, G.W. Sucrose triggers honeydew preference in the ghost ant, Tapinoma melanocephalum Hymenoptera: Formicidae. Fla. Entomol. 2015, 98, 1217-1222. [CrossRef]

29. Wilder, S.M.; Barnum, T.R.; Holway, D.A.; Suarez, A.V.; Eubanks, M.D. Introduced fire ants can exclude native ants from critical mutualist-provided resources. Oecologia 2013, 172, 197-205. [CrossRef]

30. Zhou, A.M.; Liang, G.W.; Lu, Y.Y.; Zeng, L.; Xu, Y.J. Interspecific competition between the red imported fire ant, Solenopsis invicta Buren and ghost ant, Tapinoma melanocephalum Fabricius for honeydew resources produced by an invasive mealybug, Phenacoccus solenopsis Tinsiley. Arthropod Plant Interact. 2014, 8 , 469-474. [CrossRef]

31. Zhou, A.M.; Liang, G.W.; Zeng, L.; Lu, Y.Y.; Xu, Y.J. Solenopsis invicta suppress native ant by excluding mutual exploitation from the invasive mealybug, Phenacoccus solenopsis. Pak. J. Zool. 2017, 49, 133. [CrossRef]

32. Blight, O.; Provost, E.; Renucci, M.; Tirard, A.; Orgeas, J. A native ant armed to limit the spread of the Argentine ant. Biol. Invasions 2010, 12, 3785-3793. [CrossRef]

33. Itioka, T.; Inoue, T. The alternation of mutualistic ant species affects the population growth of their trophobiont mealybug. Ecography 1999, 22, 169-177. [CrossRef]

34. Grover, C.D.; Kay, A.D.; Monson, J.A.; Marsh, T.C.; Holway, D.A. Linking nutrition and behavioural dominance: Carbohydrate scarcity limits aggression and activity in Argentine ants. Proc. R. Soc. Lond. B Biol. Sci. 2007, 274, 2951-2957. [CrossRef] [PubMed]

35. Huang, J.; Xu, Y.J.; Lu, Y.Y.; Zeng, L.; Liang, G. Effects of red imported fire ants (Hymenoptera: Formicidae) on the relationship between native ants and aphids in mung bean fields in China. Sociobiology 2010, 55, 415-426.

36. Huang, J.; Zhang, J. Changes in the photosynthetic characteristics of cotton leaves infested by invasive mealybugs tended by native ant species. Arthropod Plant Interact. 2016, 10, 161-169. [CrossRef]

37. Huang, J.; Zhang, P.J.; Zhang, J.; Tang, Y.Y. An ant-coccid mutualism affects the behavior of the parasitoid Aenasius bambawalei, but not that of the ghost ant Tetramorium bicarinatum. Sci. Rep. 2017, 7, 5175. [CrossRef]

38. Zhou, A.M.; Liang, G.W.; Zeng, L.; Lu, Y.Y.; Xu, Y.J. Interactions between ghost ants and invasive mealybugs: The case of Tapinoma melanocephalum (Hymenoptera: Formicidae) and Phenacoccus solenopsis (Hemiptera: Pseudococcidae). Fla. Entomol. 2014, 97, 1474-1480. [CrossRef]

39. Lu, Y.Y.; Wu, B.Q.; Zeng, L.; Xu, Y.J. Comparison of foraging ability between Solenopsis invicta and Tapinoma melanocephalum (Hymenoptera: Formicidae). Sociobiology 2014, 59, 1015-1024.

40. Jouvenaz, D.P.; Allen, G.E.; Banks, W.A.; Wojcik, D.P. A survey for pathogens of fire ants, Solenopsis spp., in the southeastern United States. Fla. Entomol. 1977, 4, 275-279. [CrossRef]

41. Oliver, T.H.; Jones, I.A.N.; Cook, J.M.; Leather, S.R. Avoidance responses of an aphidophagous ladybird, Adalia bipunctata, to aphid-tending ants. Ecol. Entomol. 2008, 33, 523-528. [CrossRef]

42. Errard, C.; Hefetz, A. Label familiarity and discriminatory ability of ants reared in mixed groups. Insectes Soc. 1997, 44, 189-198. [CrossRef]

43. Tsutsui, N.D.; Suarez, A.V.; Grosberg, R.K. Genetic diversity, asymmetrical aggression, and recognition in a widespread invasive species. Proc. Natl. Acad. Sci. USA 2003, 100, 1078-1083. [CrossRef] [PubMed]

44. Grangier, J.; Lester, P.J. Carbohydrate scarcity increases foraging activities and aggressiveness in the ant Prolasius advenus (Hymenoptera: Formicidae). Ecol. Entomol. 2014, 39, 684-692. [CrossRef]

45. Simpson, S.J.; Raubenheimer, D. How Does Nutrition Structure Ecosystems? The Nature of Nutrition: A Unifying Framework from Animal Adaptation to Human Obesity; Princeton University Press: Princeton, NJ, USA, 2012; pp. 120-146.

46. Yao, I.; Akimoto, S.I. Flexibility in the composition and concentration of amino acids in honeydew of the drepanosiphid aphid Tuberculatus quercicola. Ecol. Entomol. 2002, 27, 745-752. [CrossRef]

47. Helms, K.R.; Vinson, S. Plant resources and colony growth in an invasive ant: The importance of honeydew-producing hemiptera in carbohydrate transfer across trophic levels. Environ. Entomol. 2008, 37, 487-493. [CrossRef]

48. Zhou, A.M.; Lu, Y.Y.; Zeng, L.; Xu, Y.J.; Liang, G.W. Does mutualism drive the invasion of two alien species? The case of Solenopsis invicta and Phenacoccus solenopsis. PLoS ONE 2012, 7, e41856. [CrossRef] 
49. Shik, J.Z.; Kay, A.D.; Silverman, J. Aphid honeydew provides a nutritionally balanced resource for incipient Argentine ant mutualists. Anim. Behav. 2014, 95, 33-39. [CrossRef]

50. Kaneko, S. Different impacts of two species of aphid attending ants with different aggressiveness on the number of emerging adults of the aphid's primary parasitoid and hyperparasitoids. Ecol. Res. 2003, 18, 199-212. [CrossRef]

51. Kaneko, S. Predator and parasitoid attacking ant-attended aphids: Effects of predator presence and attending ant species on emerging parasitoid numbers. Ecol. Res. 2007, 22, 451-458. [CrossRef]

52. Tomalski, M.D.; Blum, M.S.; Jones, T.H.; Fales, H.M.; Howard, D.F.; Passera, L. Chemistry and functions of exocrine secretions of the ants Tapinoma melanocephalum and T. erraticum. J. Chem. Ecol. 1987, 13, 253-263. [CrossRef]

53. Xu, C.; Li, Q.L.; Qu, X.B.; Chen, J.; Zhou, A.M. Ant-hemipteran association decreases parasitism of Phenacoccus solenopsis by endoparasitoid Aenasius bambawalei. Ecol. Entomol. 2019. [CrossRef]

54. Suwabe, M.; Ohnishi, H.; Kikuchi, T.; Kawara, K.; Tsuji, K. Difference in seasonal activity pattern between non-native and native ants in subtropical forest of Okinawa Island. Jpn. Ecol. Res. 2009, 24, 637-643. [CrossRef]

55. Powell, B.E.; Silverman, J. Impact of Linepithema humile and Tapinoma sessile (Hymenoptera: Formicidae) on three natural enemies of Aphis gossypii (Hemiptera: Aphididae). Biol. Control 2010, 54, 285-291. [CrossRef]

56. Novgorodova, T.A.; Gavrilyuk, A.V. The degree of protection different ants (Hymenoptera: Formicidae) provide aphids (Hemiptera: Aphididae) against aphidophages. Eur. J. Entomol. 2012, 109, 187-196. [CrossRef]

57. Savage, A.M.; Johnson, S.D.; Whitney, K.D.; Rudgers, J.A. Do invasive ants respond more strongly to carbohydrate availability than co-occurring non-invasive ants? A test along an active Anoplolepis gracilipes invasion front. Austral. Ecol. 2011, 36, 310-319. [CrossRef]

(C) 2020 by the authors. Licensee MDPI, Basel, Switzerland. This article is an open access article distributed under the terms and conditions of the Creative Commons Attribution (CC BY) license (http://creativecommons.org/licenses/by/4.0/). 